\title{
APPLICATION OF ANTIMONIDE DIODE LASERS IN PHOTOACOUSTIC SPECTROSCOPY
}

\author{
S. Schilt and L. Thévenaz. \\ Laboratory of Metrology and Photonics (MET) \\ Swiss Federale Institute of Technology (EPFL) ,CH-1015 Lausanne, Switzerland.
}

A. Vicet, A. Perona, P. Grech and A. N. Baranov.

Centre d'Electronique et de Microoptoélectronique de Montpellier (CEM2 UMR CNRS 5507)

Université Montpellier II, 34095 Montpellier cedex 05, France.

E-mail:a.vicet@univ-montp2.fr.

Tel : 33467143471

Trace gas detection in the $2-2.5 \mu \mathrm{m}$ window is of great interest for atmospheric and industrial applications because it contains strong absorption lines of many gaseous species such as $\mathrm{CH} 4, \mathrm{CO}, \mathrm{NH} 3$, and $\mathrm{HF}$ while the water vapor absorption is weak. We report spectroscopic measurements made by photoacoustic spectroscopy at the EPFL using a GaInAsSb/GaAlAsSb based quantum well laser grown by molecular beam epitaxy at the CEM2.

The active zone of the device is made of three compressively strained $\mathrm{Ga}_{0.65} \mathrm{In}_{0.35} \mathrm{As}_{0.08} \mathrm{Sb}_{0.95}$ quantum wells between $\mathrm{Ga}_{0.70} \mathrm{Al}_{0.30} \mathrm{As}_{0.03} \mathrm{Sb}_{0.97}$ barriers. The optical confinement layers were made of $\mathrm{Ga}_{0.10} \mathrm{Al}_{0.90} \mathrm{As}_{0.07} \mathrm{Sb}_{0.93}$. The wafer was processed into $10-\mu \mathrm{m}$ ridge waveguides providing single spatial mode emission. The devices were soldered epi-side down onto copper heat sinks and placed on a Peltier cooler into a housing filled with dry nitrogen.

The laser emitted near $2.25 \mu \mathrm{m}$ in continuous wave (cw) regime at room temperature. Single frequency regime could be realized in a wide range of driving conditions, the side mode suppression ratio reaching $20 \mathrm{~dB}$.

The laser was first characterised in order to determine its optimal working conditions for photoacoustic spectroscopy. Operating parameters were determined in order to obtain a single frequency emission from the diode.

The laser was then coupled to different types of photoacoustic cells for methane concentration measurements. First, the laser emission was injected into a photoacoustic cell resonating in its first radial acoustic mode at a frequency $f=10.5 \mathrm{kHz}$ with a quality factor better than 650 . In order to improve the sensitivity of the detection, other cell configurations were evaluated. Better performances can be reached by redesigning the cell in order to take into account the divergence of the beam. Divergence angles of $20^{\circ}$ and $120^{\circ}$ have been measured, resulting in a poor coupling of the laser power in a resonant photoacoustic cell.

For this reason, a Helmholtz resonance based configuration seemed better adapted to the laser characteristics and was designed.

The first experimental results of this new geometry will be presented. 